\title{
Presencia de pautas narrativas de la tradición oral y popular en Cartucho de Nellie Campobello
}

\author{
The presence of narrative patterns from oral \\ and folk tradition in Nellie Campobello's Cartucho
}

\author{
Ana Marco González \\ Departamento de Literatura Española \\ Universidad de Granada
}

\section{RESUMEN}

Este trabajo examina la presencia de estrategias discursivas y representacionales propias de la tradición oral hispánica en uno de los testimonios más sobresalientes del ciclo narrativo de la Revolución Mexicana como es Cartucho (1931), de Nellie Campobello. En su voluntad de ofrecer una visión subjetiva, comunitaria y regionalista de las luchas entre villistas y carrancistas en el norte de México, la autora optó por reproducir historias que le habían sido transmitidas por familiares y vecinos, dando con ello lugar a un relato marcadamente polifónico y testimonial. La voz condiciona así de manera indeleble un texto en el que es perceptible además el diálogo con formas literarias del folclore mexicano, en particular con un representante destacado del género baladístico como el corrido, el cual es convocado en la prosa tanto por medio de la cita directa como por la mímesis de su poética y su lenguaje característicos.

Palabras clave: Cartucho, Narrativas de la Revolución Mexicana, Tradición Oral, Literatura Popular, Corrido.

\section{SUMMARY}

This article examines the presence of discursive and symbolic patterns from Hispanic oral tradition in one of the most significant narratives of the Mexican Revolution, Nellie Campobello's Cartucho (1931). With a view to offering a subjective, community and regionalist picture of the fights between villistas and carrancistas in the north of Mexico, the author decided to reproduce stories passed on to her by relatives and neighbours, thus creating a deeply polyphonic and testimonial tale. Hence, orality gives shape to a text where the dialogue with literary forms of the Mexican folklore is highly discernible. Particularly relevant is the dialogue maintained by Cartucho with such an outstanding expression of the ballad tradition as the corrido, which is incorporated into the prose through direct quotation, as well as through the reproduction of its typical language and poetics.

Key words: Cartucho, Narratives of the Mexican Revolution, Oral Tradition, Folk Literature, Mexican Ballad. 
Testimonio excéntrico en relación al conjunto narrativo de la Revolución Mexicana, Cartucho. Relatos de la lucha en el Norte de México (1931) ${ }^{1}$ de Nellie Campobello ha sido objeto de acercamientos críticos de signo dispar, los cuales muestran una notable falta de consenso tanto en lo relativo a la adscripción genérica del texto como en lo que se refiere a su poética rectora. Así mientras investigadores como Antonio Castro Leal (1966), María Jesús Orozco Vera (1996) y Marina González Saravia (2007) hablan respectivamente de "novela", "novela lírica" y "novela fragmentaria" ${ }^{2}$, Jorge Aguilar Mora niega la condición novelística a una obra en la que reconoce que lo histórico, lo literario, lo autobiográfico y la crónica familiar se dan la mano sin solución de continuidad (Aguilar 2000-2001: 59-60). Por su parte, Blanca Rodríguez (2007) destaca la contribución de la autora a la modernización del cuento mexicano, en tanto que Max Parra califica al conjunto de estampas de "crónica doméstica", capaz de sobreimponer a la relación infantil del impacto de la Revolución sobre la vida familiar en un pueblo de Chihuahua "una memoria regional, de donde va a derivar una visión social más abarcadora, épica, popular, de la guerra" (Parra 1998: 167).

Tampoco las directrices estéticas de su discurso son contempladas de forma unánime por quienes se han aproximado a él. Vista alternativamente como "realista" (Aguilar 2000-2001; Portal 1980) y como "anti-realista" (Keizman 2007; Pulido 2011), de naturaleza fotográfica y anclada en la "visualidad de un retrato con palabras" (Pulido 2011; Donoso 2007), tocada de surrealismo (Dessau 1972) o distinguida preferentemente por estrategias de oralización y asimilación de la voz colectiva (Parle 1985; Parra 1998), lo cierto es que la obra de la narradora mexicana resulta de difícil clasificación y compleja interpretación. Nuestro propósito en este punto pasa precisamente por desentrañar algunas claves de este particular universo narrativo, que consideramos arraiga en el realismo testimonial y memorialístico, pero que lo trasciende en diversas direcciones, poniendo de relieve su solidarización con patrones discursivos e ideológicos propios de la tradición oral de México y subrayando el diálogo sostenido por él con el corpus de la balada popular conocida como corrido.

\section{LA ORIGINALIDAD DE CARTUCHO}

Diversos factores hacen en efecto de Cartucho una obra singular. Nos hallamos en primer lugar ante una creación femenina que se inscribe en un panorama escritural dominado por hombres y que además inaugura, como ha observado con acierto Blanca Rodríguez, "una forma de narrar y un contenido no abordados por la mujer hasta ese momento". Una forma que

${ }^{1}$ En 1940 aparece la 2. ${ }^{a}$ edición de Cartucho, aumentada y con abundantes modificaciones con respecto a la original, muchas de ellas efectuadas probablemente bajo la supervisión de Martín Luis Guzmán. Esta es la versión del texto que seguiremos aquí.

${ }^{2}$ González Saravia (2007: 20) reconoce no obstante que la autora nunca se refirió al texto como a una novela y señala cómo en el prólogo a Mis libros Campobello alude a alas estampas de Cartucho" o "las narraciones de Cartucho". Sin embargo, en su opinión elementos como la temática de la guerra y la muerte, el personaje de la madre, la unidad ideológica que proporcionan el villismo y el anticarrancismo declarados, la presencia de la voz narrativa -ya en primera o en tercera persona- de Nellie Campobello y la atmósfera y el tono característicos dotarían de continuidad y unidad a la narración. 
resquebrajaría el monumento de la estética romántica a la mexicana, pues no incurre en patrones didácticos, ni moralizantes, ni críticos de las costumbres. Frente a la condición de limpidez social de las escritoras cristianas y las que educaban a las familias y a los ciudadanos, la literatura realista-naturalista de Campobello resulta fascinante porque, a semejanza de cuanto movilizaron las masas revolucionarias, la escritora desacralizó un concepto literario y una moral decimonónicos [...] (Rodríguez 1998: 65).

Por otra parte, en 1931 dicha obra emprendía una reivindicación de Villa y del villismo de carácter insólito, dado que la figura del duranguense iba a ser denostada por la institucionalidad del país más o menos hasta el ascenso al poder de Lázaro Cárdenas ${ }^{3}$. Frente a esto, Cartucho se sitúa desde un primer momento en una posición desafiante con respecto a la historiografía y la literatura precedentes, hasta el punto de que Campobello afirmará haberlo escrito "para vengar una injuria" y ofrecer una respuesta a "las novelas que entonces se escribían, [...] repletas de mentiras contra los hombres de la Revolución, principalmente contra Francisco Villa" (Carballo 1986: 410). Tampoco los avatares editoriales del libro o las confusiones que rodean a la propia biografía de la autora ${ }^{4}$ resultan ajenos a los claroscuros que se ciernen sobre su interpretación.

El carácter reactivo - frente al discurso de la oficialidad política y la literatura de la Revolución, frente al paradigma de "escritura femenina" vigente y frente a las interpretaciones centralistas de la historia de México- y la voluntad reparadora tanto de la causa villista como del sistema de valores del entorno familiar, manifiesta de forma particular en la vindicación de la actuación de la madre en los años difíciles de la contienda, son entonces responsables de buena parte de las peculiaridades del relato. A caballo entre la organicidad novelística y la acumulación de estampas independientes, este presenta una personal visión de las luchas entre villistas y carrancistas en las tierras del sur de Chihuahua y el norte de Durango, procurando, más que la evaluación objetiva de los acontecimientos, una restitución de la memoria regional en torno a los hechos y el rescate de un fragmento de biografía personal e historia familiar.

\footnotetext{
${ }^{3}$ Las fluctuaciones en la valoración del "Centauro del Norte" y de su acción militar han sido rastreadas por Max Parra (2005) en un trabajo que da cuenta de los intereses de la casta política posrevolucionaria por codificar la imagen de Villa como bandido y enemigo de la nación, en contraste con su predicamento entre las clases populares, que en buena medida lo apreciaron como a un héroe. La disensión cardenista con respecto al "grupo de Sonora", que a través de los gobiernos de Álvaro Obregón y de Plutarco Elías Calles primero y luego por medio del control ejercido por este sobre las presidencias de Emilio Portes Gil, Pascual Ortiz Rubio y Abelardo L. Rodríguez —el denominado "maximato" (1928-1934) — había prolongado su influencia en el país por más de una década, se halló entre las razones de la recuperación oficial del villismo a partir de los años treinta.

${ }^{4}$ Campobello manejó alternativamente dos fechas de nacimiento, 1909 y 1913; un acta la sitúa en 1900. En cuanto a su ascendencia, se ha especulado con la posibilidad, remota por cuestiones de cronología, de que hubiera sido hija del mismo Pancho Villa; lo fue más probablemente de un sobrino de su madre, Felipe de Jesús Moya. Además, Nellie Francisca Ernestina Campobello fue bautizada María Francisca Luna y como Soledad se conocería en la familia a su querida hermana Gloria, siendo el apellido del posible padre de Gloria, Ernst Campbell Reed, hispanizado, el que terminarían adoptando ambas. Son asimismo extraños los sucesos que rodearon a su muerte: secuestrada por motivos económicos por unos allegados en 1985, durante más de trece años se desconoció su paradero y solo tardíamente se supo de su fallecimiento en Hidalgo del Parral algún tiempo después de iniciado el rapto.
} 
Para lograr su propósito, Campobello imposta la voz y la perspectiva y asume en un gesto doblemente fingido las de la infancia durante la cual habría sido testigo junto con sus parientes de los acontecimientos que narra ${ }^{5}$. Como la propia escritora reconoce en el prólogo a Mis libros (1960: 13), adoptar el punto de vista infantil le permitía situarse en una posición en apariencia menor y más libre para alzar testimonio de aquello que se había querido silenciar; una posición desde la cual quedaba legitimada además para convertir su rememoración en un recuerdo de tipo parcial, sometido al filtro de un discernimiento y una sensibilidad muy particulares, los de una criatura de ocho o nueve años.

De esta estrategia emerge en parte una de las constantes más representativas de Cartucho: la naturalización de la violencia y el tono imperturbable e incluso lúdico con que son descritos los horrores de la lucha. En lo que constituye para Max Parra (1998: 170) un testimonio de los dispositivos psicológicos de defensa de que una niña puede servirse para superar la tensión y el temor a la muerte provocados por un episodio de guerra prolongada, Campobello presenta a menudo a su narradora-protagonista jugando con los cuerpos de los fusilados como si se tratase de sus propios muñecos o asimilando lo que sucede a su alrededor a la materia propia de un cuento de hadas. Cuando la falta de sensibilidad ante la brutalidad y la violencia se ve contrariada, es debido generalmente a la asunción del sufrimiento que la guerra causa entre los adultos:

Nunca se me ha borrado mi madre, pegada en la pared, hecha un cuadro, con los ojos puestos en la mesa negra, oyendo los insultos. El hombre aquel güero se me quedó grabado para toda la vida.

[...] Otras veces, cuando ella estaba contando algo, de repente se callaba, no podía seguir. Narrar el fin de todas sus gentes era todo lo que le quedaba (Campobello 1966: $940,944)^{6}$.

El entendimiento precario y la emotividad propios del punto de vista infantil se combinan en el relato con interpolaciones que provienen sin lugar a dudas de la perspectiva de Nellie adulta: "A mí me parecía maravilloso ver tanto soldado. [...] - ¿Qué barbaridad!'- decía mi mente niña” (936). Existe de hecho una fluctuación constante en Cartucho entre ambas instancias narradoras y evaluadoras, la infantil y la madura, y un contrapunto consecuente entre el ejercicio memorialístico-testimonial y el crítico. Y es que, como sucede con la mayor parte de las obras vinculadas al ciclo narrativo de la Revolución Mexicana, tan importante para comprender la valoración textual de los acontecimientos de la década del diez es el papel desempeñado en los mismos por los escritores, como el lugar ocupado por ellos en el establishment posrevolucionario. Campobello reproduce la experiencia infantil de la vida en una ciudad asolada por los combates, el hambre y la enfermedad desde el desencanto de saber que al fracaso villista en el campo de batalla habría de añadirse en la

\footnotetext{
${ }^{5}$ Los sucesos descritos en el libro tienen lugar mayoritariamente entre 1915 y 1919 . Si Campobello nació en 1900, su vivencia de los hechos habría sido la de una adolescente. Sin embargo, el texto es consecuente con el apunte biográfico que sitúa su nacimiento en torno a 1909, haciendo de ella una niña de unos seis a diez años durante los mismos.

${ }^{6}$ Para el presente trabajo manejaremos en todo momento la edición de 1966 de Cartucho, a cargo de Antonio Castro Leal.
} 
década de los veinte una derrota quizás aún más dolorosa, la infligida por las políticas de Obregón y Calles en el terreno del imaginario, merced a la cual los representantes del ejército convencionista serían reducidos a la categoría de bandidos y asesinos, y esta oposición anti-gobernista, junto con la activa censura a la corrupción del ideal revolucionario, moldea de manera sustancial su diálogo con el pasado.

La voluntad de reproducir la mirada de la infancia, con sus notas de espontaneidad y simplicidad aparente, se encuentra también en la base de otro de los mecanismos de desrealización puestos en funcionamiento por Nellie Campobello, quien opta por ofrecer un retrato poético de su entorno por medio del tono lírico, el empleo de un lenguaje figurativo o la opción por una imaginería y unas asociaciones metafóricas de carácter insólito.

Con estos elementos conviven sin embargo estrategias compositivas y enunciativas características de la crónica popular, las cuales permiten cumplir con otro de los propósitos fundamentales que animan el relato como es la reivindicación de una visión comunitaria de la guerra. Y es que, si además de recrear el mundo de la imaginación infantil las actitudes de la protagonista contribuyen a reproducir "el sistema de valores de la cultura local, que ella ha internalizado" (Parra 1998: 171), esta axiología y todo el patrimonio cultural que se le vincula van a conformar la matriz básica desde la que opera la narración, sobre todo en su parte última. El texto se desenvuelve entonces al socaire de los registros estilizadores propios del lirismo y la enunciación niña, pero lo hace también asumiendo dispositivos de narración y de presentación de los personajes y las anécdotas típicos de una enunciación colectiva y popular, con la que conecta tanto en virtud de su naturaleza de testimonio como por su aprovechamiento de la materia literaria tradicional, amén de por la visibilización de un conjunto de referencias y valores definitorios de una identidad regional. Veamos entonces cómo se materializan estas confluencias.

\section{LA RECUPERACIÓN DE ESTRUCTURAS PROPIAS DE LA TRADICIÓN NARRATIVA ORAL Y POPULAR}

Atenderemos aquí fundamentalmente a dos manifestaciones narrativas de la tradición oral en español vigentes en México en la primera mitad del siglo XX, el cuento folclórico y el corrido. Las dos pueden considerarse populares en función de su circulación informal entre amplios sectores de población, buena parte de ellos "subalternos" en un sentido gramsciano (Gramsci 1968: 330), y que participan además en mayor o menor medida en la creación y re-creación de las muestras. Estas resultan en efecto del manejo de una serie de recursos temáticos, formales y estilísticos conocidos y compartidos por la mayor parte del cuerpo social, con lo que nos hallamos ante una "estética colectiva", popular asimismo en el sentido de que se desenvuelve en los márgenes de un horizonte de expectativas acotado que solo muy ocasionalmente busca trascender, a diferencia de lo que sucede con la creación considerada "culta". Este hecho no es óbice sin embargo para que muchos de estos recursos compositivos puedan proceder originariamente de repertorios catalogados como "cultos".

Con independencia de esto, cuentos folclóricos y baladas exhiben además una serie de rasgos que han sido relacionados de manera específica con una poética propia 
de lo oral, resultante de las necesidades impuestas por la vocalización y la transmisión en presencia ${ }^{7}$. Asimismo, la permanencia constatada de testimonios de ambos géneros y de su acervo de arquetipos y patrones compositivos en el patrimonio cultural de varias generaciones (al menos desde la segunda mitad del siglo XIX y aun antes, si se considera a su precedente el romance en el caso del corrido; con posibilidad de remitir algunos temas y peculiaridades formales a la cuentística medieval y de los Siglos de Oro para el relato) y su supervivencia conforme a una dialéctica de permanencia y variación, en la que conviven la creación original de muestras, la reproducción memorística de las mismas y la gestación de variantes distintivas de los prototipos originales como consecuencia de su ejecución en presencia, permiten atestiguar su calidad tradicional ${ }^{8}$.

Memorialístico en tanto que rescata las vivencias de la infancia-adolescencia de la autora, un trabajo como Cartucho se revela a la vez altamente testimonial, al provenir sus anécdotas tanto de la observación directa como de los relatos que proporcionan a la escritora diversos informantes en un período coetáneo o no demasiado alejado del tiempo en el que tuvieron lugar los hechos. La plasmación de la visión norteña de los sucesos revolucionarios da pues lugar a una narración con una fuerte impronta oral y polifónica, que se teje a partir de las combinaciones de voces y ecos de otras voces en un intento de asimilarse a la exposición colectiva propia del relato anónimo de circulación popular. No en vano la narradora-personaje se presenta en buena parte del libro como locutora de historias de otros — fundamentalmente, aunque no solo, historias que le fueron contadas por su madre- Hablan por ejemplo en él Nellie niña, Mamá, el tío, Pepita Chacón, Chonita, Martín López, El Siete, Ismael Máynez, Isaías Álvarez o numerosas mujeres anónimas del Norte. Resulta significativa en este sentido la abundancia de verba dicendi que nutre el discurso, un aspecto que junto a la revelación de las circunstancias bajo las cuales el narrador fue informado de la materia que presenta

\footnotetext{
${ }^{7}$ Las marcas comparativas (inferioridad con respecto a lo escrito) y teleológicas (estadio primitivo y previo a la aparición de la verdadera literatura, la escrita) que el concepto de "literatura oral" ha llevado aparejadas desde su acuñación en 1881 por Paul Sébillot, junto con el oxímoron contenido en la asociación de los dos términos, "letra" "oral", han conducido a numerosos autores a rechazar el marbete. Paul Zumthor optaría en cambio por asumirlo en su Introducción a la poesía oral (1991), otorgando carácter literario a lo que el público, lectores y oyentes, recibe como tal, si bien a partir de La letra y la voz (1989) preferirá reservar el término "literatura" para hacer referencia a un tipo de discurso específico sujeto a la realidad de la sociedad burguesa de las dos últimas centurias aproximadamente. Nosotros empleamos aquí la expresión en el sentido en que es manejada por Zumthor en su trabajo de 1991.

${ }^{8}$ Resulta no obstante fundamental reparar en la compleja articulación de categorías como "tradicional" y "popular" aplicadas a este tipo de manifestaciones. En el caso del corrido, por ejemplo, convergen en su poética aportes del romancero tradicional, centrado en la transmisión oral, y del juglaresco, que contaba con un transmisor especializado, el juglar, y pronto sometido a la transmisión en pliegos y cancioneros, así como de los denominados romances "vulgares", "de ciego" o "de cordel", o de la copla. Sobre todos ellos ejercerá además tempranamente una notable influencia la transmisión mediatizada a través de grabaciones fonográficas. (Para profundizar en el multidireccional diálogo que en el ámbito del discurso corridístico se desarrolla entre lo oral y lo escrito, la transmisión en presencia y la mediatizada, los acervos considerados tradicionales, los populares y los vulgares, véase González 2011 y Hernández 1986 y 1992. Para una reflexión de similares características aplicada al relato folclórico de transmisión oral, resultan útiles trabajos como los de Pedrosa 2010 o Díaz Viana 2010).
} 
intensifica esta calidad comunitaria del arte de contar. También la constatación de la condición de testigo presencial de los acontecimientos que unos y otros reiteran o la precisa localización topográfica de los hechos son propias de una oralidad de corte tradicional, que busca con ello acentuar su verosimilitud:

Fue allí, en el cuartel de Jesús, en la primera calle del Rayo; lo vio mi tío, él se lo contó a mamá y lo cuenta cada vez que quiere (959).

Salvador es de la calle Segunda del Rayo; nació allí, fue de la gente de José Rodríguez. Le contó a mamá algo de Carlos Almeida, algo del combate con Tomás Rivas. [...] Dijo que a José lo habían matado en una traición y que José para acá y José para allá. Dijo muchas cosas (947).

Todos comentaban aquel fusilamiento; dijo mamá que hasta lloraban por Pablito; ella no lo vio, porque estaba en Parral. Martín se lo contó todo (946).

Mataron al Perico Rojas, a González, a Chato Estrada. Fusilaron a los Martínez. Se perdió en el combate Sosita, y así se pasaban las noticias de boca en boca (962)9.

Existen incluso casos de múltiple narración enmarcada, a la manera de "cajas chinas":

Dice Chonita contenta de recordarlo:

- Hacía mucho aire, los sombreros nomás se les pandeaban en la cabeza. [...] Las gentes que los vieron los recuerdan todavía. "Sí, cómo no, sí — dicen las señoras-, por allí iba Nicolás Fernández, alto, delgado..." (966).

Un trasiego de dimes y diretes que conviene a una exposición focalizada, capaz de distorsionar u ocultar el calado de ciertos hechos, como cuando la polémica muerte de Tomás Urbina, atribuida a la voluntad de Francisco Villa, parece resolverse en una mera cuestión de sagacidad por parte del general de Durango:

Le contaron a mamá todo lo que había pasado. Ella no lo olvidaba. Aquellos hombres habían sido sus paisanos. Fue en Nieves — dijo mamá [...]. Contaron que al general Villa le había sorprendido mucho la noticia de la muerte de su compadre Urbina, pero todos supieron que Fierro le dijo que Urbina se andaba volteando y que realmente él había tenido que intervenir a balazos. Mamá decía que todo se debió a una corazonada del jefe de la División del Norte (Campobello 1966: 942) ${ }^{10}$.

\footnotetext{
${ }^{9}$ Los subrayados son nuestros.

${ }^{10}$ M. Parra considera este relato como uno de los que mejor revelan las estrategias puestas en práctica por la autora para reproducir la cosmovisión regional popular en torno al conflicto armado. Ajusticiado Urbina a instancias de Rodolfo Fierro por haber abandonado el sitio de El Ébano en 1915 para pactar con el carrancismo, la colectividad resolvería el compromiso que le suponía presentar como un desertor al otrora compadre de Villa y paisano suyo (Urbina había nacido en el distrito de Ocampo, en Durango, y la mayoría de los vecinos de la zona se declaraban urbinistas) desplazando el núcleo del conflicto desde el terreno de lo militar al de las pasiones íntimas. Campobello se hace eco en Cartucho del modo en que la leyenda transformó una maniobra política en un acto de despecho amoroso, al sostener que el general había abandonado su puesto para comprobar la fiabilidad de los rumores que lo señalaban como víctima de traición por parte de su esposa, adoptando con ello uun patrón común de la narrativa popular, [que] atribuye la caída del héroe a una decepción amorosa" (Parra 1998: 180-182). Al sostener que "Urbina, general, fracasó ante Urbina, hombre" (948), el relato refrenda una interpretación de los hechos que silencia la deserción ideológica y humaniza al traidor al convertirlo en
} 
La precisión topográfica típica del libro contrasta sin embargo con la ausencia de menciones al año en que tienen lugar los acontecimientos, rasgo que conviene a una perspectiva intrahistórica, doméstica, y que con ello participa también de fórmulas narrativas propias de la leyenda. En esta línea abundan las caracterizaciones esquemáticas e incuestionables de personas y sucesos que se presentan más bien como la constatación de hechos por todos conocidos: "Elías Acosta era famoso por villista, por valiente y por bueno" (930). A esta impresión contribuye además la adopción en un buen número de ocasiones del estilo formulístico propio de la poesía narrativa oral, sobre todo para la introducción de los personajes, donde se hacen muy evidentes las reminiscencias de las fórmulas de apertura del corrido:

Salvador es de la calle Segunda del Rayo. Nació allí, fue de la gente de José Rodríguez (947).

Pablito Siáñez había nacido en Cerro Gordo, Durango. Cuentan los que lo trataron que fue un hombre muy valiente (961).

Antonio se llamaba, era jefe de la brigada Villa (932).

Lo mataron aquí, en Parral, allá por el mesón de El Águila (962).

Así rezan corridos como el de "Palomón":

En el año del catorce, tiempo de Revolución, en ese pueblo de Allende mataron a Palomón.

Fue soldado muy valiente de la gente de Elizondo, y lo iban a fusilar en el pueblo de Paso Hondo (Hernández 1996: 97),

el de "Valentín Mancera":

Año de mil ochocientos, ochenta y dos muy presente, murió Valentín Mancera que era un hombre muy valiente.

[...] Valentín nace en San Juan y en San Juan de Dios murió, y Sanjuana se llamaba la infeliz que lo vendió (Hernández 1996: 22- 23),

o el de "Agapito Treviño":

En el cañón de Huajuco, estado de Nuevo León, allí habitaba Agapito un hombre de corazón (Avitia 1997, t. I: 99),

una víctima de sus propios sentimientos. Con ello se contradecía de paso la versión externa (urbana, letrada y centralista) en torno al suceso y se salvaguardaba la actuación del propio Villa, al tiempo que la honorabilidad de Urbina. 
por citar solo algunos ejemplos tomados de los ciclos corridísticos de rebeldes y bandoleros y del de la Revolución Mexicana.

Con respecto al estilo desplegado en Cartucho, cabe también considerar la relación del texto con matrices propias de la narración oral, como la abundancia de repeticiones de todo tipo (fónicas, léxicas, sintácticas, temáticas...), al igual que el predominio de la parataxis, la frase corta y el ritmo ágil. Blanca Rodríguez (2007: 619) ha subrayado la conexión existente entre el lenguaje rápido y elíptico de los cuentos de Campobello con la voluntad de la autora de representar la oralidad del español del Norte de México, con su intención declarada de escribir como se hablaba, así como con el contexto inmediato en que se gestan y transmiten los argumentos de Cartucho, un espacio familiar, habitado sobre todo por mujeres que compartían las noticias y las historias de la guerra para apaciguar su angustia mientras protegían a sus hijos y esperaban quizá el regreso de sus hombres.

No hay que olvidar en todo caso que a las peculiaridades de ese estilo femenino destacado por Rodríguez se suman por lo menos otras dos características fundamentales para la configuración de la urdimbre discursiva global de las estampas: su condición parcial de narración poemática, caracterizada por el abandono a la expresión lírica, y su connivencia con formas literarias propias de la tradición oral, algunas, como el corrido, alejadas por lo común de una vocalización femenina. Es asimismo de la mano de la balada -bien a través del aporte intertextual, bien por medio de la mímesis de sus procedimientos discursivos - como penetran en parte a la prosa dialectalismos, arcaísmos, formas regionales de enunciación, etc., o como es posible reconocer en ella una marcada querencia por la frase breve, el período octosilábico, la yuxtaposición y la elipsis.

La mímesis del lenguaje norteño y de formas orales vernáculas conduce a que frente a lo que es propio de buena parte de la novelística de la Revolución Mexicana no se observe en el libro un acusado contraste entre la expresión del narrador y la de los personajes. Si bien el habla de estos últimos exhibe una mayor querencia por el diminutivo y un uso más frecuente del modismo dialectal, en su conjunto el texto incurre en el localismo de forma más bien somera y asistimos antes a una ficcionalización de la oralidad regional que a su transposición directa. Esta impresión se ve acentuada por el recurso de Campobello a una particular estrategia narrativa, que posibilita que sea una tonalidad única la que domine la narración. En realidad, la escritora solo caracteriza individualmente las voces que incorpora en algunas ocasiones y el modo prevaleciente de la narración es el de lo que Graciela Reyes (1984: 198) denomina oratio quasi oblicua, por el que el discurso del otro es asumido como propio, casi o completamente:

La oratio quasi-oblicua consiste en una frase articulada, modelada, re-traducida por el locutor de una declaración ajena. Esa re-formulación personalizada se ajustaría mejor, conforme a la hermenéutica del locutor, al significado de las palabras dichas o atribuidas por el 'enunciador'. La frase pertenece a otro, otro es el responsable de ella (Reyes 1984: 1980).

Sin embargo, el discurso ajeno es asumido al máximo, "hasta el punto de que podría afirmarse que locutor y enunciador coinciden" (74), pese a que la fuente de la noticia sea ajena. Dicha fuente es conocida, si bien "el locutor reformula de tal modo el enunciado previo que, haciéndolo suyo, garantiza su valor de verdad" (74-75). El pasaje en el que Nellie Campobello reproduce el encuentro entre uno de sus conoci- 
dos, Severo, y Pancho Villa ("La voz del general") es uno de los que mejor ejemplifican el modo en que la escritora recurre a este proceder. El pasaje se inicia con una frase del narrador — "Metálica y desparramada. Sus gritos fuertes, claros, a veces parejos y vibrantes. Su voz se podía oír a gran distancia, sus pulmones parecían de acero" (958)_, a la que sigue una cita directa de las palabras del amigo: «Severo me lo dice: Fue en San Alberto, junto a Parral». A partir de ahí, Nellie va a reproducir lo que Severo le contó, pero en sus propios términos. Sin embargo, todo lo que dice —así como su valoración inicial de la voz de Villa- le ha sido transmitido por el joven, fuente original del discurso. La escritora está reproduciendo entonces un discurso ajeno, si bien lo hace desde la materialidad del suyo propio. Entremezclado con este, aunque en una proporción menor, introducirá otra vez en estilo directo supuestos pasajes del diálogo sostenido por los protagonistas de la acción:

Severo había salido en los momentos del combate para ir a ver a su novia; pero, como era civil, podían tomarlo por espía; eso lo pensó hasta que llegó a San Alberto, lugar adonde estaba el general Villa, acompañado de unos quinientos hombres. Severo se fue a la casa de su novia; para evitar sospechas le dijeron que se pusiera a partir leña en el patio de la casa. Villa se dio cuenta de que aquel joven no era de allí. Lo estuvo viendo, y luego, paso a paso, se acercó y le dijo: "Oye, hijo: ¿qué dejaste de nuevo en Parral?; tú acabas de llegar". Severo, bastante sorprendido, le contestó rápido: "Sí, general; vengo de Parral y dejé a los villistas agarrados en las zanjas. Yo pasé como pude y con bastante trabajo, porque el tiroteo era muy fuerte y los muchachos estaban muy apurados" (958).

Domina entonces por lo general en Cartucho una sola voz locutora, aunque el origen de la enunciación sea múltiple, y es la capacidad de esa voz para estilizar las pautas claves de la narración oral en el español del norte de México la que permite que, cuando existe cita directa de la palabra de otros, como en el caso de la incorporación de corridos, no se dé una brusca variación tonal o estilística en el seno del texto.

También la mayor parte de los protagonistas de las estampas responden a demandas representativas del discurso literario oral, dada su falta de densidad psicológica, su condición de figuras tipo o su naturaleza hiperbólica. La exigencia del acontecimiento grandioso y la personalidad extraordinaria ha sido vinculada en numerosas ocasiones con la técnica de la oralidad en función de sus virtudes mnemotécnicas y por su capacidad para decantar valores y conductas paradigmáticos. Por otro lado, si el contraste con lo cotidiano convierte a seres y acciones en memorables, el rechazo de la ambigüedad en la evaluación de las situaciones hace que su asunción resulte más sencilla y su perdurabilidad más profunda, resultados enormemente convenientes en situaciones informativas que se desarrollan en presencia y con escasa posibilidad - $\mathrm{O}$ directamente sin ella- de recurrir al registro escrito (Ong 2002: 139), justo el tipo de universo comunicacional que Campobello desea recrear.

Otra de las claves que explica la particular convivencia en el seno de Cartucho entre patrones discursivos de corte realista, en el sentido que el racionalismo ha terminado por imponer al término, y prácticas de alguna manera "desrealizadoras", y que además refuerza su vinculación con un entorno cultural popular, es su opción por un modelo de escritura fundado en no poca medida en el grotesco. Frente a la extendida atribución de realismo stricto sensu a las estéticas populares, un investigador como Jesús Martín Barbero (1987: 87-88) halla por ejemplo más consecuente con ellas una noción como la de "realismo grotesco", evaluada ampliamente por Bajtin en La 
cultura popular de la Edad Media y el Renacimiento (1965), y que funcionaría por exageración y degradación y no por calco. El grotesco constituiría además una estrategia para superar el horror propia de la mecánica relacional de la expresión folclórica ${ }^{11}$ que Campobello despliega por lo común omitiendo tanto lo accesorio como lo "esperable" en la descripción de personajes y ambientes y centrando en cambio su atención en detalles poco relevantes pero que llaman poderosamente la atención de la narradora-niña o de sus conciudadanos. El episodio de la muerte de Luis Herrera refleja bien esa capacidad del grotesco para vincular lo espantoso con lo jovial y el modo en que aquel es vehiculado frecuentemente en Cartucho por medio de la expresión metonímica, tropo que favorece además una transmutación lírica de la violencia: "Ese desgraciado, qué bien murió [...]. Tenía el desgraciado la cara espavorida, como viendo al diablo. 'Qué feo estaba', decían tosiendo de la risa" (952) ${ }^{12}$.

Nos encontramos en todos los casos ante rasgos que se acomodan de manera muy natural al proyecto estético de Campobello, por lo menos al que la escritora consolida en la segunda edición de Cartucho, la de 1940, que ha quedado como definitiva pese a la introducción de algunas alteraciones menores en la posterior de 1960. El texto se instala ahora de manera muy firme en la recuperación de la voz colectiva, expandiendo el alcance de su rememoración desde su núcleo inicial, de carácter si no exclusiva, sí más marcadamente personal, centrado en episodios que la niña ha visto o vivido de primera mano. El incremento de la dimensión comunitaria se realiza pues progresivamente, tanto en un sentido cronológico - buena parte de las modificaciones y los añadidos que contribuyen a su intensificación se introducen en el período comprendido entre finales de la década de los veinte y la de los treinta-, como en el que atañe a la propia disposición de los cuadros — será en la parte última del libro, y sobre todo en su tercera sección, donde esa presencia de la enunciación múltiple vaya a resultar más clara-. En su conjunto, la edición de 1940 elimina uno de los treinta y tres relatos iniciales, el titulado "Villa", y añade al volumen veinticuatro historias nuevas, algunas fruto del trabajo de campo efectuado en el intervalo por la autora, quien entrevistaría a combatientes veteranos como Ismael Máynez o a la propia viuda de Villa, Austreberta Rentería, y recopilaría una importante serie de corridos y de leyendas regionales. Además, la edición original contenía dos prólogos luego eliminados, uno obra del poeta estridentista Germán List Arzubide, a quien se atribuye asimismo la ordenación de las estampas previa a la publicación y su división en tres secciones — "Hombres del norte", "Fusilados" y "En el fuego"—, y otro atribuible a la propia Nellie (Rodríguez 2007).

En relación a las modificaciones de corte estilístico operadas sobre la edición del cuarenta, la crítica ha puesto de manifiesto la probable influencia ejercida sobre la autora por Martín Luis Guzmán, quien habría estimulado la eliminación de coloquialismos y la sujeción del texto a un mayor decoro o a una idea general de corrección

\footnotetext{
${ }^{11}$ Estrategia en la que lo alto se vincula a lo bajo, la inteligencia a la estupidez, la locura a la cordura o la risa al llanto (Molho 1976).

${ }^{12}$ Transposición como la operada en pasajes como los siguientes: "El Kirilí se quedó dentro del agua, enfriando su cuerpo y apretando, entre los tejidos de su carne porosa, unas balas que lo quemaron" (Campobello 1966: 930); "Me quedé sin voz, con los ojos abiertos, sufrí tanto, se lo llevaban, tenía unos balazos, vi su pantalón, hoy sí era el de un muerto" (33).
} 
culta (Aguilar 2000). Margo Glantz y Blanca Rodríguez subrayan también cómo Cambopello, quizá de nuevo influida por Guzmán, tiende a mitigar aquí la dimensión erótica subyacente al relato original, por la que este daba cabida a un erotismo intrínsecamente ligado a la cercanía de la muerte y al panorama de precariedad, enfermedad y suciedad propio de la guerra (Glantz 2003: 33-36; Rodríguez 1998: 185).

Las modificaciones incorporadas en la edición de 1940 acentúan en términos generales la vecindad de Cartucho con el terreno de lo legendario, de forma que dos planos contrapuestos terminan por concurrir en su conformación retórica e ideológica: el del registro histórico, atento a la fijación de acontecimientos efectivamente acaecidos; el que resulta de su transmutación a un plano superior de significación por el que aquellos se revisten de un espesor simbólico, espesor representativo de un conjunto de experiencias compartidas del que emerge por decantación un sistema de valores capaces de proporcionar sentido y guía a la existencia. Evidentemente, Campobello logra esto último en buena medida en virtud del diálogo que su prosa mantiene con el folclore de su región natal, en particular con manifestaciones como el corrido.

\section{CANCIONES Y CORRIDOS EN CARTUCHO}

Representante del multiforme dominio de la balada pan-hispánica, el corrido constituye sin duda uno de los emblemas más poderosos del patrimonio melódico mexicano. El género hunde sus raíces en el romance peninsular, que llevado a América por los conquistadores incrementará en el nuevo continente el repertorio de sus muestras, toda vez que terminará por dar lugar a prácticas originales en las diferentes áreas. En México, a partir del siglo XIX la tradición del romance se manifestará con unas características lo suficientemente definidas como para que podamos hablar del corrido en tanto que género diferenciado de su antepasado ibérico ${ }^{13}$. Compuesto habitualmente en cuartetas octosílabas con rima en los versos pares, la división estrófica y la rima variable lo alejan por ejemplo de la preferencia del romance tradicional por la tirada monorrima. No obstante, el romance — tradicional y vulgar- seguirá constituyéndose como la base que proporciona a los corridistas estructuras, temas y personajes básicos con los que estos elaboran relatos basados en las vivencias y las problemáticas de su entorno (Hernández 2000: 235). Dichos relatos se enmarcan en una estructura fuertemente tipificada, cuyo diseño suele ir pautándose en la propia composición por medio de una serie de expresiones formulaicas que contribuyen a rellenar nudos básicos del hilo argumental y de su diseño pragmático (así la llamada inicial del intérprete al pú-

\footnotetext{
${ }^{13}$ Pese a que la opinión más extendida entre los especialistas es la que defiende la formación del corrido a partir de una tradición baladística americana que se habría ido constituyendo sobre la base del romance español desde los tiempos de la Colonia (véanse al respecto Simmons 1963, Mendoza 1997 o Hernández 1992), lo cierto es que investigadores de reconocido prestigio como Américo Paredes (1963: 231-235) localizan sus orígenes en tanto que tradición folclórica autónoma en la franja fronteriza entre México y los Estados Unidos y lo vinculan al intenso conflicto intercultural generado por las actuaciones expansionistas estadounidenses en la región de Texas a lo largo del siglo XIX, el cual habría sido propicio a una expresión folclórica de naturaleza épica.
} 
blico, la fijación del lugar y la fecha de los acontecimientos relatados, la presentación del protagonista de la historia, la exposición de un mensaje que la refiere, la despedida del personaje o el saludo del propio cantor). Frente a lo sostenido por un sector de la crítica, el propósito fundamental de estas composiciones no pasaría tanto por informar, por constituirse en un medio de difusión de noticias, como por interpretar hechos sentidos como notables en el seno de las comunidades entre las que tiene lugar su gestación y su circulación, y de ahí que las historias sean presentadas por lo común de modo que adquieran una dimensión ejemplar.

Si en el conjunto narrativo de la Revolución Mexicana las alusiones a fiestas y fandangos, la consignación de actuaciones de corridistas profesionales, la descripción de instrumentos o la incorporación de personajes músicos resultan más que frecuentes, dando cuenta entre otros aspectos de la querencia del ciclo por los usos costumbristas, estas no escasean ni mucho menos en Cartucho, por cuyas páginas canta ostentosamente el Kirilí, Bartolo entona una y otra vez el "desterrado me fui" o se presenta al general Agustín García recurriendo a la música para consolarse del robo frustrado de una joven que ama: "Se puso a cantar 'prieta orgullosa, no te vuelvo a ver la cara'" (Campobello 1966: 932). Pero amén de este tipo de referencias, la relación del texto de Campobello con la música popular, y en concreto con la tradición del corrido, es mucho más íntima y sustancial, y se manifiesta además de dos formas diferentes: de un lado, se hace patente en virtud de la vecindad temática y estilísticodiscursiva de la prosa con patrones propios de la poética corridística; de otro, la escritora convoca abiertamente a las melodías populares mediante la cita intertextual de fragmentos de baladas así como de canciones norteñas.

La reelaboración de pautas de la narración oral popular próximas a las que guían la concepción narratológica del corrido es en parte responsable como señalábamos de la querencia de las estampas por la frase corta, el ritmo ágil, la ausencia de digresiones, la unión paratáctica de los enunciados, la preferencia por un léxico de tipo concreto, el apoyo en enumeraciones, repeticiones y exageraciones o el recurso a lo formulístico $^{14}$. Reiteraciones de todo tipo (fonéticas, semánticas, sintácticas) sostienen de este modo el avance del discurso:

Ella era coronela y usaba pistola y tenía trenzas (935).

La esposa de uno de los fusilados llegó a Parral, mandó sacar los cuerpos, los vio mucho rato, luego ordenó cajas para los tres y mandó que cerraran las tres tumbas con una reja de hierro (949).

Llegó a general, porque sabía tratar hombres y tratar bestias.

Llegó a general, porque sabía de balazos y sabía pensar con el corazón (948).

Y nada más decía: “Fusílenlos luego, luego, luego; fusílenlos luego, luego, luego”, y firmaba. Estaba mandando matar a muchos, muchos, muchos, muchísimos (954).

\footnotetext{
${ }^{14}$ La presencia en Cartucho de enumeraciones, reiteraciones, agrupaciones sintácticas octosilábicas y determinadas rimas internas de tipo asonantado que refuerzan la vecindad de algunos de sus pasajes con estructuras versales próximas a las del período corridístico ha sido analizada con detalle por Dennis J. Parle (1985).
} 
¡Cuánta gente hay viendo morir a mi hermano! Mire usted, señora, mire: aquí ya está muerto. ¿Cuándo me moriré para morir como él? —decía, dándose cabezazos contra las paredes- (951).

El recurso a la repetición como estrategia discursiva y performativa grata al corrido se hace patente una y otra vez en el repertorio del género. Sirva como muestra estos fragmentos de la versión del fronterizo "Corrido de Gregorio Cortés", originario de principios del siglo XX, que Jorge Cervera Sánchez comunicó al investigador Vicente T. Mendoza en la Ciudad de México en 1953:

Decía Gregorio Cortés con su arma aún encendida: -No siento haberlo matado, la defensa es permitida.

Decía Gregorio Cortés con su pistola en la mano: - No siento haberlo matado, lo que siento es a mi hermano.

[...] Siguió con rumbo a Laredo sin ninguna timidez:

—Síganme "rinches" cobardes, yo soy Gregorio Cortés.

Siguió con rumbo a Laredo, varios cherifes lo vieron, no lo quisieron prender, porque le tuvieron miedo.

Allá por "El Encinal" alcanzaron a rodear, poquitos, más de trescientos, allí les brincó el corral.

Allá por los matorrales y según a lo que dicen, se agarraron a balazos y allí mató otro cherife.

Decían los americanos: —Y ahora, ¿cómo le haremos? Si le entramos por derecho, muy poquitos volveremos.

Decía Gregorio Cortés con su pistola en la mano: — iNo corran "rinches" cobardes, ante un solo mexicano! (Mendoza 1964: 205.)

Repetitivos resultan también en Cartucho tanto la forma de organizar los relatos como el diseño macro-estructural del conjunto. A la manera del corrido, buena parte de las viñetas narran momentos culminantes de la vida de los revolucionarios del campo de Chihuahua, casi siempre teñidos de violencia. Constituyen aquellas así una 
suerte de recuento individualizado (en el sentido etimológico de "contar", que Corominas vincula a computare) de una larga serie de muertes trágicas y como la propia narradora reconoce, se trata de alguna manera de canciones sin música: "Jamás imaginó [Pablo Mares] que yo le hiciera este verso sin ritmo" (961). Es más, en no pocos casos, los pasajes dan cuenta de una estructura circular que los asemeja al corrido, de modo que anuncian como este un final trágico y pasan luego a relatar los antecedentes de la ejecución, arribando en último término al punto de partida. Así sucede con la narración de la muerte de Pablo López, el célebre soldado villista participante en el asalto a la ciudad norteamericana de Columbus en marzo de 1916. El pasaje, titulado "La muleta de Pablo López", se abre directamente con la mención de la muerte del joven: "Todos comentaban aquel fusilamiento; dijo mamá que hasta lloraban por Pablito; ella no lo vio, porque estaba en Parral. Martín se lo contó todo. Lloraba mucho y le dijo 'que quería morir como su hermano Pablito, muy valiente, muy hombre'" (946). En este punto la narradora, siguiendo a su madre, inicia una retrospección en la que se va a dar cuenta de los sucesos que ocasionaron el fatal desenlace: "Pablito López un día mandó fusilar a unos americanos. 'No los fusile -le dijeron a algunos hombres-. ¿No mira que son americanos?’”. En la conclusión de la estampa se retorna al punto inicial, centrado en el hecho mismo del fusilamiento:

Lo fusilaron frente al pueblo. (Existen muchos retratos de este acto.) Como última voluntad pidió el no morir frente a un americano que estaba entre la multitud. 'No quiero morir frente a ese', dijo, con energía, el tímido y joven general.

Las balas lo bajaron de su muleta y lo tendieron en el suelo. Sus heridas de Columbus ya no lo molestaban.

Yo creo que aquel coronel Del Arco se perfumaría el bigote, apretaría su triunfo entre el tubo de sus botas de militar elegante, y seguramente se fue marcando sus pisadas y creyendo en su importancia (946).

Reiterando este esquema, la mayor parte de las viñetas integradas en la sección "Los Fusilados" vienen precedidas de un nombre propio a manera de título, nombre que no es otro que el del soldado cuya muerte se va a relatar brevemente a continuación: "Epifanio", "Zafiro y Zequiel", "Nacha Ceniceros", "El centinela del mesón de 'El Águila'”, "El general Rueda”, "La muerte de Felipe Ángeles»...

Este es también el patrón narrativo al que se acogen tantísimos corridos de fusilados, traiciones y ajusticiamientos. Así opera por ejemplo el compositor de la versión del "Corrido de Macario Romero" grabada en 1908 por el dúo Ábrego y Picazo en la Ciudad de México, quien en las dos primeras estrofas del poema, amén de introducir el nombre de su protagonista, el militar Macario Romero, supuestamente asesinado por la oposición del padre de su enamorada a sus relaciones, da noticia de su trágico fin. El resto de la balada va a aplicarse a detallar las causas y los pormenores de la muerte del valiente, para volver a constatar esta en su última cuarteta:

Voy a cantar, mis amigos, con cariño verdadero, para recordar del hombre que fue Macario Romero.

Era amigo de los hombres, los quería de corazón; 
por un amor lo mataron,

lo mataron a traición.

[...] Dijo Jesusita Llamas:

-Ahora sí quedamos bien,

ya mataron a Macario,

mátenme ahora a mí también. "Macario Romero" (Hernández 1996: 24-25).

Idéntico es el proceder del corridista que relata la captura y ejecución del prófugo y soldado revolucionario Benito Canales, oriundo del estado de Michoacán. La narrativa, ateniéndose a un patrón tradicional, incidirá en el hecho de que Canales fue apresado por la traición de una mujer:

Año de mil novecientos

en el trece que pasó,

murió Benito Canales,

el Gobierno lo mató.

Andaba tienda por tienda

buscando tinta y papel,

para escribirle una carta

a su querida Isabel.

[...] Aquí termina el corrido

de don Benito Canales,

una mujer tapatía

lo entregó a los federales.

Ya con esta me despido

al pie de bellos rosales,

aquí se acaban los versos

de don Benito Canales. (Mendoza 1964: 188-190.)

Por otro lado, la yuxtaposición que ordena el material estilístico de la obra de Campobello y que se reitera al nivel arquitectónico contribuye a inclinar decididamente ciertos pasajes del lado de la crónica, convirtiéndolos en un puro relato de acción en el que la calidad sintética de la prosa es máxima. El texto asume de este modo uno de los rasgos formales básicos del arte oral, tanto en el plano del discurso como en el de la intriga, como es del del decir elíptico. Zumthor recuerda por ejemplo que "se ha comprobado que los cuentos de tradición oral solo tienen descripciones si son maravillosas, es decir, si sirven para rechazar las circunstancias presentes" (1991: 57). Y aquí se localiza también otro punto de confluencia entre Cartucho y el universo de la balada popular-tradicional, pues la tendencia a la esencialidad y a la elipsis constituye una de las características más llamativas de la poética corridística. Los autores y las audiencias del género suelen compartir un conocimiento previo tanto de los hechos narrados como de las convenciones del estilo, lo que permite al compositor privilegiar los efectos alusivos e impresivos de su narración en detrimento del despliegue minucioso, o por lo menos sustancial, de las peripecias centrales de los episodios que recrea.

Esta estrategia se hace muy evidente en un corrido como el de "Jesús García", el célebre "héroe de Nacozari", Sonora, quien en 1907 evitó una tragedia al redirigir un tren en llamas cargado de dinamita que avanzaba hacia la ciudad de Nacozari fuera 
de la misma, mientras sus compañeros se ponían a salvo. Finalmente el convoy explotó en los aledaños de la localidad, muriendo trece personas, entre ellas el mismo García, pero salvándose los cinco mil habitantes de Nacozari (Avitia 1997, I: 255). En la versión recogida por Antonio Avitia, el anónimo compositor anuncia el relato de "lo que en Nacozari pasó", pero se limita a resaltar la generosidad y valentía del maquinista:

Como a las dos de la tarde,

como a esas horas serían

cuando murió el héroe:

el héroe Jesús García (Avitia 1997, I: 254),

quien es retratado además pidiéndole a la Virgen su muerte a cambio de la salvación de Placeritos (el mineral de Placeritos adonde García se había trasladado de niño junto con su familia), un gesto que no hace sino destacar su abnegación:

Concédeme, Virgen querida,

de llegar a Puertecitas,

más que yo pierda la vida, que se salve Placeritos.

El otro vector de la narración pasa por destacar las consecuencias del estallido de la pólvora, tanto sobre el propio héroe como sobre el resto de víctimas, y en resaltar cómo la memoria del mártir es venerada por los habitantes de la zona. No se incluye ni una mención a los trenes más allá de la contenida en el verso "mira que ya el primer carro, / ya se nos viene quemando", ni aparece ni una mínima digresión que explique que García decidió permanecer al frente de su máquina para desviar el convoy. El baladista busca en cambio destacar los aspectos más llamativos, por lo escabroso, sentimental o ejemplar, de unos acontecimientos que supone conocidos por su auditorio.

Tampoco un público ignorante de la relevancia de una figura como Benjamín Argumedo, guerrillero oriundo de Matamoros, Cohauila, adherido en un principio a la causa maderista y sucesivamente orozquista, huertista, zapatista y convencionista después, podría tomar conciencia de la misma a tenor de lo narrado por una composición como "El fusilamiento de Benjamín Argumedo". El corrido, transmitido por tradición oral, hoja suelta y diversas grabaciones fonográficas, y uno de los más paradigmáticos del ciclo de la Revolución Mexicana como ha sido puesto de manifiesto por James Nicolopulos (2010), recupera el prendimiento, traslado a la penitenciaría y posterior ejecución del conocido como "León de la Laguna", centrándose en el diálogo sostenido por este con el general carrancista Francisco Murguía y en la despedida previa a su fusilamiento, notablemente desarrollada en algunas variantes, en las que el militar pide sepultura cristiana, reconoce la vanidad del mundo, manifiesta temor o saluda a su tierra y sus seres queridos. Poco más se nos cuenta de la historia, aunque los escasos acontecimientos que se desgranan resultan ser rigurosamente históricos.

Para ponerme a cantar pido permiso primero, son las mañanas, señores, de Benjamín Argumedo. 
Doy detalle en realidad

que fue el veintiocho de enero

aprehendieron a Alanís

y a Benjamín Argumedo.

Benjamín anda en la sierra,

en la sierra de Durango,

cuando supo que Murguía

pues ya lo andaba buscando.

[...] — ¡Válgame Dios, qué haré yo?—

dijo al general Murguía,

ahí le pidió una merced,

a ver si la concedía.

[...] -Adiós también el reloj,

sus horas atormentaban

pues clarito me decía

las horas que me faltaban. (Hernández 1996: 51-53.)

Como el corrido, el conjunto de estampas de Cartucho prevé un público parcialmente informado y procura no tanto la presentación de hechos nuevos y desconocidos como aclarar el significado verdadero de sucesos por todos sabidos.

Pero el diálogo entre la prosa de Campobello y el corrido no afecta solo a cuestiones formales y pragmáticas, sino que se manifiesta también como venimos apuntando en relación a la temática y la visión del mundo desplegada por ellos. Ambos centran sus relatos en la descripción de la acción y el enfrentamiento con la muerte de sus protagonistas, haciendo gala de una intencionalidad tributaria que les lleva a aureolar a hombres y hechos con un toque legendario. De ahí que muchos de los personajes del libro queden definidos por su acción generosa y valiente - o bien cobarde y traidora - en un instante crucial, y sean convertidos por lo mismo en paradigmas de conducta. Y de ahí que, descritos la mayoría en forma impresionista, apenas sí conozcamos algún detalle de la fisonomía y de las costumbres de los hombres y mujeres sobre los que la niña Francisca posa su mirada:

José Rodríguez había nacido en Satevó; un día se volvió general villista; valiente, joven, sabía montar a caballo, conocía la sierra, estuvo en muchos combates, y en todas las peleas los hombros fuertes y anchos de José Rodríguez se abrían paso dejando enemigos caídos (947).

Antonio Silva se llamaba, era jefe de la brigada Villa; fue uno de los generales que menos hicieron travesuras; valiente y atravesado, pero jamás dio qué decir en Parral ni en la Segunda. Había nacido en San Antonio del Tule, allá por Balleza. Era alto y prieto; tenía una pierna más corta y usaba un tacón para emparejarse el paso (932).

Ángeles era muy hombre

$\mathrm{y}$ de un valor sin segundo

que bien se podía decir

que no había otro en el mundo.

[...] De artillero comenzó

su carrera militar

y al poco tiempo ascendió

a ser un gran general. "Corrido de Felipe Ángeles" (Hernández 1996: 55-57). 


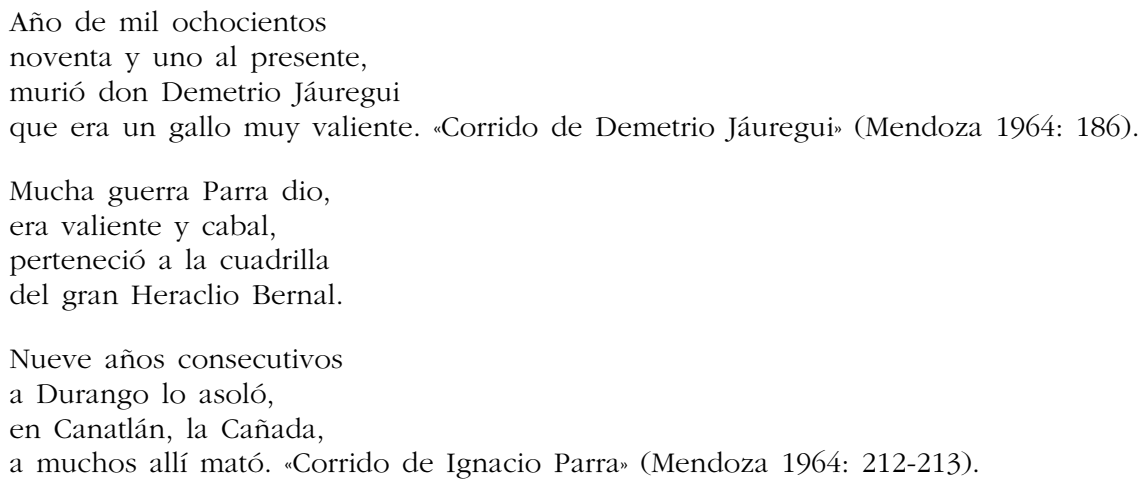

Además, canciones y corridos entran a la prosa a través de su convocatoria intertextual. En la parte final de Cartucho se citan por ejemplo los corridos de Abelardo Prieto y de Martín López, se incorporan fragmentos de una canción popular de Chihuahua y de otra de la autoría de Campobello en torno a los jóvenes de la Segunda del Rayo, la calle donde transcurre la infancia revolucionaria de Francisca y el núcleo espacial desde donde irradia la narración. ¿Cuál es la función de estas citas? En primer lugar, los corridos ofrecen a la autora una plataforma alternativa para incorporar a su texto voces de reconocida ajenidad, capaces de certificar su interpretación de los hechos y de hacerlo además desde el punto de vista regional que el libro reivindica y busca recuperar:

Le contaron a mamá todo lo que había pasado. Ella no lo olvidaba. Aquellos hombres habían sido sus paisanos (942).

Puros hombres de Durango estaban matando. Paisanos de nosotros (954).

Decían que aquellos hombres eran unos bandidos; nosotros sabíamos que eran hombres del norte, valientes, que no podían moverse, porque sus heridas no los dejaban (953).

La presencia de corridos en el texto escrito adquiere por todo esto un cariz revindicativo: la apelación a la voz, con su ilusión de inmediatez, fortalece los lazos de pertenencia a una comunidad amenazada por un orden externo y más fuerte, recurriendo así la escritora a la virtualidad del folclore para actualizar el sentido de la Gemeinschaft o colectividad aglutinada en torno a lazos afectivos, intereses y vinculaciones culturales comunes. Además, como sucede con la mayor parte de los ensayos de inserción de canciones en la prosa literaria, subyace aquí un deseo de hacer explícita la pertenencia a una tradición de la que Nellie y sus vecinos se saben no solo receptores, sino también creadores activos: "Cada uno tenía una canción preferida y la fueron dejando de herencia a los que la quisieron" (962). El canto se presenta entonces como el espacio de lo no institucionalizado, vía para la restauración de una memoria y una identidad que han sido silenciadas y que sin embargo son defendidas como fundamentales para la comprensión de la verdadera historia de México: "A Mamá, que me regaló cuentos verdaderos en un país donde se fabrican leyendas y donde la gente vive adormecida de dolor oyéndolas "15 (929).

\footnotetext{
${ }^{15}$ Esta cita se presenta como dedicatoria del libro en su segunda edición (Cf. Aguilar 2000: 73).
} 
El juego intertextual con la materia corridística intensifica a su vez la mitificación del acontecimiento histórico operada por Cartucho, contribuyendo a favorecer su perduración en el recuerdo. La autora es claramente consciente de la forma en que la balada puede servir para redimir la memoria de aquellos que han conocido un destino adverso y de ahí que, hacia el final del libro, afirme por ejemplo: "Los que todavía recuerdan a Abelardo cantan la tragedia. Son así las deudas entre hombres; se pagan con canciones y balas. [...] Abelardo Prieto está vengado" (965). La historia de este joven oriundo de San Ignacio, en El Tule, Chihuahua, que se unió tempranamente a la causa de Villa y murió junto con su padre en una emboscada cuando tenía veintiún años, se presenta en el relato al alimón con la narración del corrido. El interés por consignar el trágico suceso y la elevación de Prieto a emblema de la valentía y la capacidad de sacrificio de los jóvenes norteños dan cuenta de la manera en la que, lejos de optar por una anotación exhaustiva de fechas, batallas y datos, la escritora opera conforme a la lógica cultural de la narración popular, en la que la calidad de la comunicación está lejos de ser proporcional a la cantidad de la información manejada (Martín Barbero 1987), y se asienta más bien sobre criterios que tienen que ver con valores de significatividad, ejemplaridad, pertinencia, etc.

Otro de los episodios organizados de manera más clara en torno al diálogo con el folclore regional es el que gira en torno a la figura de Martín López ("Las hojas verdes de Martín López"), en el que la inclusión del corrido en torno al militar villista opera como una suerte de glosa o paráfrasis del texto de la escritora. Aquí la voz corridística entona en una segunda voz un acontecimiento ya narrado, de manera que si la prosa presenta la historia del lugarteniente de Villa, querido por él como un hijo y herido de muerte por tropas carrancistas durante el asalto a la ciudad de Durango en 1919, el corrido contribuye a amplificar, como el coro de la tragedia clásica, el sentido de lo contado, dando cuenta del respeto y el cariño de que gozaba su figura en las tierras del Norte:

\footnotetext{
Pancho Villa lo lloraba, lo lloraban los Dorados, lo lloró toda la gente, hasta los más encuerados.

Todos los cerros del Norte recordarán a Martín, a caballo los subió sin miedo de irse a morir.

Vuela, paloma ceniza, vete pa'aquella humareda, y diles que Martín López aquí se quedó en la sierra.
}

La canción y, más aún, el acto de su ejecución compartida, conforman en suma para la autora imágenes poderosas de unión y de solidaridad colectiva. Es así que en la conclusión de Cartucho los oficiales de Segunda del Rayo, jóvenes de cuya muerte se nos ha ido dando noticia, cantan su canción, «juntando sus voces y haciendo una rueda" (966). 
En las noches su canto sigue testereando sobre las puertas, ellos se barajan en la sombra para dejarse ver con la luna; sus cuerpos se alargan, yo creo que quieren parecer fantasmas de cuentos para niños miedosos (968).

\section{CONCLUSIÓN}

Nellie Campobello buscó deliberadamente con Cartucho dar cuenta de la identidad cultural de una amplia franja del norte de México, entre los estados de Chihuahua y Durango, por medio de la recuperación de la memoria popular de la zona en torno a los sucesos revolucionarios. Su texto asume una perspectiva local, testimonial y anclada en las poéticas de la oralidad en relación a la causa villista, oponiéndose con ello a los discursos historiográfico y novelístico sancionados desde los centros urbanos de poder. Su lógica no es por eso la del informe o la crónica en sentido estricto, sino que opera a partir de la reconstrucción subjetiva del modo en que los hechos fueron interpretados y sentidos en torno suyo. Entre las diversas estrategias de que se sirve para recrear esta visión -mediatización de la tragedia por la perspectiva imperturbable de una narradora niña, recorte de la perspectiva y presentación fragmentaria de los acontecimientos, privilegio de lo doméstico, lenguaje e imaginería ocasionalmente líricos... - sobresale la recreación de un discurso polifónico capaz de rescatar una sensibilidad de corte familiar y comunitario ante los hechos armados.

Precisamente esta voluntad de la autora de recuperar literariamente los episodios de la revolución villista a partir de la reescritura de historias que circulaban de viva voz entre los habitantes del norte de México donde transcurrieran su infancia y adolescencia, o que conocía por haber quedado consignados por leyendas y canciones populares, le lleva a alumbrar una prosa atravesada por un buen número de rasgos definidos por la etnolingüística como propios de los "géneros literarios orales". Con preferencia por los particulares concretos y por un léxico básico, flexibilizando la lengua con la moderada incorporación de diminutivos y regionalismos, y aprovechando las múltiples posibilidades de la repetición, Campobello da lugar en Cartucho a un lenguaje que se sitúa a caballo entre lo poético y lo cronístico y que con ello guarda más de un punto de contacto con la norma corridística.

Más allá de las innegables connivencias temáticas entre muchos de los relatos y el corrido, pues además de su inspiración en el suceso histórico el libro no hace sino culminar la expresión de violencia y muerte de aquel, ambos coinciden en su predilección por la frase corta, el ritmo ágil, la escasa digresión, la unión paratáctica de los enunciados, la preferencia por un léxico de tipo concreto, el apoyo en enumeraciones, repeticiones y exageraciones o el recurso a lo formulístico. La información que ambos ponen a nuestra disposición es relativamente escasa, pero uno y otro la someten a una elaboración impresiva característica de la comunicación oral. El volumen recurre asimismo a la inserción de corridos y canciones en el cuerpo del texto, una convocatoria en la que tienden a aprovecharse las implicaciones reivindicativas y emocionales del trabajo con manifestaciones asociadas a la oralidad y a una ejecución performancial, su contribución al enriquecimiento estilístico de la prosa y su capacidad para ofrecer una interpretación plural de acontecimientos que de este modo aparecen presentados no ya únicamente por boca del narrador, sino por una vocalización ajena y solidaria con un sector de la 
memoria popular. Tras este estilo colectivo del decir la autora advierte además un claro trasfondo filosófico y cultural que desea igualmente preservar.

En definitiva, por medio de un texto en el que lo personal y lo comunitario se imbrican de manera insoslayable, Nellie Campobello acierta a dar forma a uno de los testimonios más originales de la literatura surgida al hilo de la Revolución Mexicana, una suerte de "corrido en prosa" capaz de recoger en un nivel distinto de significación el ánimo de los revolucionarios villistas y sus gentes.

\section{BIBLIOGRAFÍA CITADA}

Aguilar Mora, J. 2000-2001. "El silencio de Nellie Campobello". Kipus. Revista Andina de Letras 12: 55-78.

Avitia, A. 1997-1998. Corrido histórico mexicano: voy a cantarles la historia, 5 vols. México D. F: Porrúa.

Barroso Villar, E. (ed.). 1996. Narrativa de la Revolución Mexicana. La Revolución en las artes y en la prensa. (Conferencias de los Encuentros I y II sobre el Ciclo Narrativo de la Revolución Mexicana). Sevilla: Universidad de Sevilla / Fundación El Monte.

Campobello, N. 1960. Mis libros. México D. F.: Compañía General de Ediciones.

Campobello, N. 1966. Cartucho. Relatos de la lucha en el norte de México, en Castro Leal, A. (comp.), La novela de la Revolución Mexicana. Tomo I: 929-969. México D. F.: Aguilar.

Campobello, N. 2002. Las manos de Mamá / Tres poemas / Mis libros. México D. F.: Factoría Ediciones.

Carballo, E. 1986. "Nellie Campobello", en Protagonistas de la literatura mexicana: 408-419. México D. F.: SEP.

Castro Leal, A. (comp.). 1966. La novela de la Revolución mexicana. 2 vols. México D. F: Aguilar.

Cázares H., L. (ed.). 2006. Nellie Campobello. La Revolución en clave de mujer. México D. F.-Monterrey: Universidad Iberoamericana / CONACULTA / Tecnológico de Monterrey.

Dessau, A. 1972. La novela de la Revolución Mexicana. México D. F: FCE.

Díaz Viana, L. (coord.). 2000. Palabras para el pueblo. Volumen 1. Aproximación General a la Literatura de Cordel. Madrid: CSIC.

Díaz Viana, L. 2010. "Memoria y oralidad: la documentación de los recuerdos. (Problemas teóricos y metodológicos en el registro de la cultura inmaterial)", en Actas del Simposio sobre Literatura Popular de la Fundación Joaquín Díaz: 124-141. Edición digital: http://www.funjdiaz.net/ pubactas.cfm (Consultada 20-12-2012).

Donoso, C. 2007. "Retrato hablado. La austera visualidad de los relatos de Nellie Campobello". Revista de crítica literaria lationamericana XXXIII (66): 173-186.

Glantz, M. 2003. "Vigencia de Nellie Campobello". Anales de Literatura Española 16 (6): 5-38.

González, A. 2011. "El corrido: expresión popular y tradicional de la balada hispánica”. Olivar 15: 15-36.

González Saravia, M. 2007. Cartucho. Hacia la reconfiguración de la realidad. Tesis de Maestría. Colima: Universidad de Colima.

Gramsci, A. 1968. Cultura y literatura. Barcelona: Península.

Hernández, G. 1986. "La Punitiva: El corrido norteño y la tradición oral, fonográfica e impresa" Heterofonía 29 (3): 46-64.

Hernández, G. 1992. "El corrido ayer y hoy: nuevas notas para su estudio", en Valenzuela Arce, J. M. (comp.), Entre la magia y la bistoria. Tradiciones, mitos y leyendas de la frontera: 215-229. Tijuana: El Colegio de la Frontera Norte.

Hernández, G. (ed.). 1996. The Mexican Revolution Corridos. El Cerrito (California): Arhoolie Folklyrics Records.

Hernández, G. 2000. "El corrido de la Martina o romance de la Blancaniña: una cadena narrativa milenaria en versiones orales, impresas y electrónicas", en Díaz Viana, L. (coord.), Palabras para el pueblo. Volumen 1. Aproximación General a la Literatura de Cordel: 227-244. Madrid: CSIC. 
Keizman, B. 2007. "Entre el testimonio y la autobiografía: Cartucho y la construcción de una memoria poética/política". CILHA 9: 35-39.

Mariscal, B. y Miaja, M. T. (eds.). 2007. Actas del XV Congreso de la Asociación Internacional de Hispanistas. Tomo IV. Literatura hispanoamericana siglos XIX, XX y XXI. México D. F.: FCE / AIH / El Colegio de México / Tecnológico de Monterrey.

Martín Barbero, J. 1987. De los medios a las mediaciones: comunicación, cultura y hegemonía. Barcelona: Gustavo Gili.

Mendoza, V. T. 1964. Lírica narrativa de México. El corrido. México D. F.: UNAM.

Mendoza, V. T. 1997. El romance español y el corrido mexicano. Estudio comparativo. México D. F.: UNAM.

Molho, M. 1976. Cervantes: raíces folclóricas. Madrid: Gredos.

Nicolopulos, J. 2010. "Algunos datos sobre el corrido de 'El fusilamiento del General Argumedo'" http:/ /www.laits.utexas.edu/jaime/jrn/benargpt3.html (Consultada 8-10-2010).

Ong, W. 2002. Oralidad y escritura. Tecnologías de la palabra. México D. F.: FCE.

Orozco Vera, M. J. 1996. "La mujer y la Revolución Mexicana en Cartucho y Las manos de mamá, de Nellie Campobello", en Barroso Villar, E. (ed.), Narrativa de la Revolución Mexicana. La Revolución en las artes y en la prensa. (Conferencias de los Encuentros I y II sobre el Ciclo Narrativo de la Revolución Mexicana): 271-282. Sevilla: Universidad de Sevilla / Fundación El Monte.

Paredes, A. 1998. With his Pistol in his Hand. A Border Ballad and its Hero. Austin: University of Texas Press.

Parle, D. J. 1985. "Narrative Style and Technique in Nellie Campobello's Cartucho". Kentucky Romance Quarterly 32: 201-211.

Parra, M. 1998. "Memoria y guerra en Cartucho, de Nellie Campobello". Revista de crítica literaria latinoamericana XXIV (47): 167-186.

Parra, M. 2005. Writing Pancho Villa's Revolution. Austin: University of Texas Press.

Pedrosa, J. M. 2010. "¿Literatura oral? ¿Tradicional? ¿Popular? ¿Mitología popular?”, en, Actas del Simposio sobre Literatura Popular de la Fundación Joaquín Díaz: 31-38: http://www.funjdiaz.net/ pubactas.cfm (Consultada 20-12-2012).

Portal, M. 1980. Proceso narrativo de la Revolución Mexicana. Madrid: Espasa Calpe.

Pulido Herráez, B. 2011. "Reseña de Cartucho. Relatos de la lucha en el norte de México de Nellie Campobello". Revista de Literatura Latinoamericana 52: 31-51.

Reyes, G. 1984. Polifonía textual. Madrid: Gredos.

Rodríguez, B. 1998. Nellie Campobello: eros y violencia. México D. F.: UNAM.

Rodríguez, B. 2002. "Prólogo", en Campobello, N., Las manos de Mamá / Tres poemas / Mis libros: 527. México D. F.: Factoría Ediciones.

Rodríguez, B. 2007. "La guerra como placer estético en Cartucho", en Mariscal, B. y Miaja, M. T. (eds.), Actas del XV Congreso de la Asociación Internacional de Hispanistas. Tomo IV. Literatura hispanoamericana siglos XIX, XX y XXI: 611-619. México D. F.: FCE / AIH / El Colegio de México / Tecnológico de Monterrey.

Simmons, M. 1963. "The Ancestry of Mexico’s Corridos". Journal of American Folklore 76 (299): 1-15.

Valenzuela Arce, J. M. (comp.). 1992. Entre la magia y la historia. Tradiciones, mitos y leyendas de la frontera. Tijuana: El Colegio de la Frontera Norte.

Zumthor, P. 1989. La letra y la voz. De la "literatura" medieval. Madrid: Cátedra.

Zumthor, P. 1991. Introducción a la poesía oral. Madrid: Taurus.

Fecha de recepción: 20 de abril de 2012

Fecha de aceptación: 26 de febrero de 2013 